\title{
Age- and sex-dependent changes of resting amygdalar activity in individuals free of clinical cardiovascular disease
}

\author{
Ahmed Haider, PhD, ${ }^{\mathrm{a}, \mathrm{b}}$ Susan Bengs, PhD, ${ }^{\mathrm{a}, \mathrm{b}}$ Flavia Diggelmann, MSc, ${ }^{\mathrm{a}, \mathrm{b}}$ \\ Gioia Epprecht, BSc, ${ }^{\mathrm{a}, \mathrm{b}}$ Dominik Etter, BSc, ${ }^{\mathrm{a}, \mathrm{b}}$ Anna Luisa Beeler, BSc, ${ }^{\mathrm{a}, \mathrm{b}}$ \\ Winandus J. Wijnen, PhD, ${ }^{\mathrm{a}, \mathrm{b}}$ Valerie Treyer, PhD, ${ }^{\mathrm{a}}$ Angela Portmann, MSc, ${ }^{\mathrm{a}, \mathrm{b}}$ \\ Geoffrey I. Warnock, PhD, , ${ }^{\mathrm{a} b}$ Muriel Grämer, PhD, , a \\ Tobias A. Fuchs, MD, a Aju P. Pazhenkottil, MD, ${ }^{\mathrm{a}, \mathrm{c}}$ Ronny R. Buechel, $M D,{ }^{\mathrm{a}}$ \\ Felix C. Tanner, MD, ${ }^{c}$ Philipp A. Kaufmann, MD, ${ }^{a}$ Catherine Gebhard, MD, \\ $P h D,{ }^{a, b}$ and Michael Fiechter, MD, PhD ${ }^{a, b, d}$ \\ a Department of Nuclear Medicine, University Hospital Zurich, Zurich, Switzerland \\ b Center for Molecular Cardiology, University of Zurich, Schlieren, Switzerland \\ c Department of Cardiology, University of Zurich, Zurich, Switzerland \\ d Swiss Paraplegic Center, Nottwil, Switzerland
}

Received Nov 10, 2020; accepted Dec 17, 2020

doi: $10.1007 / \mathrm{s} 12350-020-02504-7$

Purpose. Amygdalar metabolic activity was shown to independently predict cardiovascular outcomes. However, little is known about age- and sex-dependent variability in neuronal stress responses among individuals free of cardiac disease. This study sought to assess age- and sexspecific differences of resting amygdalar metabolic activity in the absence of clinical cardiovascular disease.

Methods. Amygdalar metabolic activity was assessed in 563 patients who underwent multimodality imaging by ${ }^{18} \mathrm{~F}$-fluorodeoxyglucose $\left({ }^{18} \mathrm{~F}\right.$-FDG) positron emission tomography/computed tomography and echocardiography for the evaluation of cardiac function.

Results. After exclusion of 294 patients with structural or functional cardiovascular pathologies, 269 patients (128 women) remained in the final population. ${ }^{18} \mathrm{~F}$-FDG amygdalar activity significantly decreased with age in men $(r=-0.278, P=0.001)$, but not in women $(r=0.002, P=0.983)$. Similarly, dichotomous analysis confirmed a lower amygdalar activity in men $\geq 50$ years as compared to those $<50$ years of age $(0.79 \pm 0.1$ vs. $0.84 \pm 0.1, P=0.007)$, which was not observed in women $(0.81 \pm 0.1$ vs. $0.82 \pm 0.1, P=0.549)$. Accordingly, a fully adjusted linear regression analysis identified age as an independent predictor of amygdalar activity only in men (B-coefficient $-0.278, P=0.001)$.

Supplementary Information The online version of this article (h ttps://doi.org/10.1007/s12350-020-02504-7) contains supplementary material, which is available to authorized users.

The authors of this article have provided a PowerPoint file, available for download at SpringerLink, which summarizes the contents of the paper and is free for re-use at meetings and presentations. Search for the article DOI on SpringerLink.com.

The authors have also provided an audio summary of the article, which is available to download as ESM, or to listen to via the JNC/ASNC Podcast.

Funding CG was supported by grants from the Swiss National Science Foundation (SNSF), the Olga Mayenfisch Foundation, Switzerland, the OPO Foundation, Switzerland, the Novartis
Foundation, Switzerland, the Swissheart Foundation, and the Helmut Horten Foundation, Switzerland. SB was supported by the Swissheart and UZH Foundation, AH was supported by the UZH Foundation, and MF was supported by the Swiss Paraplegic Center, Nottwil, Switzerland.

Ahmed Haider and Susan Bengs have contributed equally.

Reprint requests: Michael Fiechter, MD, PhD, Department of Nuclear Medicine, University Hospital Zurich, Raemistrasse 100, 8091

Zurich, Switzerland; Michael.Fiechter@usz.ch

J Nucl Cardiol

1071-3581/\$34.00

Copyright (c) 2021 The Author(s) 
Conclusion. Amygdalar activity decreases with age in men, but not in women. The use of amygdalar activity for cardiovascular risk stratification merits consideration of inherent ageand sex-dependent variability. (J Nucl Cardiol 2021;28:427-32.)

Key Words: Amygdala $\cdot$ aging $\cdot$ sex differences $\cdot$ heart-brain axis $\cdot$ emotional stress $\cdot{ }^{18} \mathrm{~F}$ fluorodeoxyglucose $\left({ }^{18}\right.$ F-FDG) $\bullet$ positron emission tomography (PET) • echocardiography $•$ cardiovascular disease $\cdot$ risk stratification

See related editorial, pp. 433-435

\section{INTRODUCTION}

Cardiovascular disease remains the primary cause of death in Europe, accounting for mortality rates of $49 \%$ and $40 \%$ in women and men, respectively. ${ }^{1}$ In particular, there is increasing evidence for sex differences in the pathophysiology of coronary artery disease (CAD), including the female propensity towards non-obstructive CAD, coronary microvascular dysfunction, and stress (Takotsubo) cardiomyopathy, thus prompting reassessment of traditional cardiovascular risk conditions. ${ }^{2}$ As such, considerable efforts have been devoted to understand how emotional stress is translated into adverse cardiovascular outcomes.

The brain's salience network, an ensemble of interconnected brain regions responsible for emotional stress responses, has recently gained increasing attention within the context of CAD. Indeed, a recent landmark study demonstrated that the resting amygdalar metabolic activity, a key element of the brain's salience network, independently predicted cardiovascular outcomes. ${ }^{3}$ Further, increased amygdalar activity was linked to impaired myocardial perfusion and function in women, but not in men, which is in agreement with the higher incidence of stress cardiomyopathy in women. ${ }^{4,5}$ Despite the detrimental association of enhanced amygdalar activity in CAD patients, little is known about neuronal stress responses in individuals free of cardiac disease. Understanding how the resting amygdalar activity is affected by age and sex in the absence of cardiac disease, however, is crucial for accurate risk assessment in CAD patients. Thus, we sought to assess age- and sexspecific differences of amygdalar metabolic activity in individuals free of clinical cardiovascular disease.

\section{METHODS AND RESULTS}

A total of 563 patients underwent clinically indicated oncologic whole-body ${ }^{18} \mathrm{~F}$-fluorodeoxyglucose $\left({ }^{18} \mathrm{~F}\right.$-FDG $)$ positron emission tomography (PET)/computed tomography (CT) and echocardiography to assess cardiac function according to current guidelines. ${ }^{6}$ After exclusion of 294 patients with impaired left ventricular ejection fraction (LVEF $<50 \%$ ), presence of wall-motion abnormalities, history of coronary artery disease (PCI, CABG, previous myocardial infarction), and/or diabetes, 269 patients (128 [48\%] women) free of clinical cardiovascular disease remained in the final study population. None of these patients had metabolically active malignancies. After measurement of patient's blood glucose level $(5.5 \pm 1.2$ $\mathrm{mmol} / \mathrm{L}$ in women and $5.8 \pm 1.4 \mathrm{mmol} / \mathrm{L}$ in men, $P=0.11$ for women vs. men), a dose of $\sim 350 \mathrm{MBq}{ }^{18} \mathrm{~F}$-FDG was injected into a peripheral vein. Following tracer injection, individuals were allowed to rest for 45-60 minutes before a standardized PET image acquisition protocol, which includes non-contrast CT, was applied. Whole-body scans were cropped for the skull and quantitative assessment of resting amygdalar activity was performed as previously described. ${ }^{4}$ Briefly, serial regions of interest (ROI) were placed in both amygdalae to measure ${ }^{18}$ F-FDG standardized uptake value (SUV) by use of PMOD software V4.1 (PMOD Technologies LLC, Zurich, Switzerland) and application of the brain maximum probability map (Hammersmith atlas, ${ }^{7}$ ). Normalization was performed against cerebellar activity. PET/CT and echocardiography were performed within a maximum time frame of 3 months. Pearson's $r$ was applied to investigate associations, whereas linear regression models were used to identify predictor variables. The study was reviewed and approved by the institutional review board (BASEC No. 201701112). The ethics committee waived the need for informed consent due to the retrospective study design.

As depicted in Table 1, patient baseline characteristics were comparable between women and men, with the exceptions of smoking (women vs. men, $9.4 \%$ vs. $20.6 \%, P=0.011$ ), left ventricular ejection fraction (LVEF, women vs. men, $62.9 \pm 5.5$ vs. $60.7 \pm 6.0$, $P=0.002$ ), and creatinine levels (women vs. men, $85.1 \pm 79.2$ vs. $118.4 \pm 97.5, P=0.028)$. The mean age was $57.4 \pm 16.3$ years in women and $59.0 \pm 13.5$ years in men. Pearson's $r$ correlation analysis showed a weak and negative association between age and ${ }^{18} \mathrm{~F}-\mathrm{FDG}$ amygdalar uptake in the whole study population $(r=-$ $0.132, P=0.030$, Figure 1A). When stratified by sex, this relation was not observed in women $(r=0.002$, $P=0.983$, Figure 1B), but was pronounced and inverse in men $(r=-0.278, P=0.001$, Figure $1 C)$. Dichotomous analysis confirmed a significantly lower amygdalar activity in men $\geq 50$ years as compared to those $<50$ years of age $(0.79 \pm 0.1$ vs. $0.84 \pm 0.1$, $P=0.007$, Figure $2 \mathrm{~A}$ ). In contrast, there was no difference in amygdalar activity in women $\geq 50$ vs. $<50$ years of age $(0.81 \pm 0.1$ vs. $0.82 \pm 0.1, P=0.549$, Figure 2B). Stepwise linear regression analysis for ${ }^{18} \mathrm{~F}$ FDG amygdalar uptake as a dependent variable and age, 
hypertension, dyslipidemia, obesity, positive family history for $\mathrm{CAD}$, or smoking as predictor variables identified age as sole independent predictor for amygdalar activity in men $(B$-coefficient $-0.278, P=0.001)$. In the whole study population, an interaction term consisting of age and male sex was selected as an independent predictor for amygdalar activity in a linear regression model ( $B$-coefficient $-0.200, P=0.001)$.

\section{DISCUSSION}

Taken together, we observed age- and sex-dependent alterations of amygdalar activity in individuals free of clinical cardiovascular disease. While amygdalar activity significantly decreased with age in men, women showed no age-related changes in amygdalar activity.
Accordingly, age was selected as an independent negative predictor of amygdalar activity in men, but not in women. These findings imply that the use of resting amygdalar metabolic activity for cardiovascular risk stratification, as suggested in a recent landmark study by Tawakol et al, ${ }^{3}$ merits careful consideration of age and sex as potential confounders.

Chronic psychosocial stress is an established cardiovascular risk factor. Nonetheless, the mechanisms that translate emotional stress into cardiovascular events remain poorly understood. ${ }^{8}$ Among the suggested mechanisms, the concept that increased amygdalar activity results in enhanced hematopoiesis in the bone marrow, thus contributing to arterial inflammation and subsequent worsening of CAD is particularly intriguing. 3,9 Our study implies that amygdalar metabolic activity is

Table 1. Patient baseline characteristics

\begin{tabular}{|c|c|c|c|c|}
\hline $\begin{array}{l}\text { Patient baseline } \\
\text { characteristics }\end{array}$ & $\begin{array}{c}\text { Total } \\
\mathrm{n}=\mathbf{2 6 9}\end{array}$ & $\begin{array}{l}\text { Women } \\
n=128\end{array}$ & $\begin{array}{c}\text { Men } \\
\mathrm{n}=141\end{array}$ & $\begin{array}{l}\text { P-value (women } \\
\text { vs. men) }\end{array}$ \\
\hline Age (years), mean $\pm S D$ & $58.2 \pm 14.9$ & $57.4 \pm 16.3$ & $59.0 \pm 13.5$ & 0.397 \\
\hline Hypertension, n(\%) & $82(30.5)$ & $39(30.5)$ & $43(30.5)$ & 1.000 \\
\hline Dyslipidemia, n(\%) & $18(6.7)$ & $7(2.6)$ & $11(4.1)$ & 0.475 \\
\hline Obesity, n(\%) & $39(14.5)$ & $19(14.8)$ & $20(14.2)$ & 1.000 \\
\hline Family history of CAD, n(\%) & $3(1.1)$ & $1(0.8)$ & $2(1.4)$ & 1.000 \\
\hline Smoking, $n(\%)$ & $41(15.2)$ & $12(9.4)$ & $29(20.6)$ & 0.011 \\
\hline Alcohol, $\mathrm{n}(\%)$ & $18(6.7)$ & $6(4.7)$ & $12(8.5)$ & 0.232 \\
\hline $\operatorname{LVEF}(\%)$, mean $\pm S D$ & $61.2 \pm 5.8$ & $62.9 \pm 5.5$ & $60.7 \pm 6.0$ & 0.002 \\
\hline Blood glucose $(\mathrm{mmol} / \mathrm{l})$, mean \pm SD & $5.6 \pm 1.3$ & $5.5 \pm 1.2$ & $5.8 \pm 1.4$ & 0.105 \\
\hline Creatinine $(\mu \mathrm{mol} / \mathrm{l})$, mean $\pm \mathrm{SD}$ & $102.3 \pm 90.4$ & $85.1 \pm 79.2$ & $118.4 \pm 97.5$ & 0.028 \\
\hline $\mathrm{CRP}(\mathrm{mg} / \mathrm{l})$, mean $\pm \mathrm{SD}$ & $53.5 \pm 68.8$ & $47.0 \pm 66.6$ & $59.2 \pm 70.8$ & 0.302 \\
\hline NT-proBNP (ng/l), mean \pm SD & $1553 \pm 2468$ & $1204 \pm 2524$ & $2018 \pm 2418$ & 0.398 \\
\hline Neutrophils $\left(\times 10^{3} / \mu \mathrm{l}\right)$, mean \pm SD & $5.8 \pm 3.5$ & $6.2 \pm 4.1$ & $5.5 \pm 2.9$ & 0.237 \\
\hline Lymphocytes $\left(\times 10^{3} / \mu \mathrm{l}\right)$, mean \pm SD & $1.3 \pm 0.8$ & $1.4 \pm 0.8$ & $1.3 \pm 0.7$ & 0.159 \\
\hline${ }^{18} \mathrm{~F}-\mathrm{FDG}$ bone marrow (SUV), mean $\pm \mathrm{SD}$ & $1.9 \pm 0.5$ & $1.9 \pm 0.5$ & $1.9 \pm 0.5$ & 0.434 \\
\hline${ }^{18} \mathrm{~F}$-FDG amygdala (rSUV), mean \pm SD & $0.8 \pm 0.1$ & $0.8 \pm 0.1$ & $0.8 \pm 0.1$ & 0.388 \\
\hline ACE, $n(\%)$ & $38(14.2)$ & $20(15.6)$ & $18(12.9)$ & 0.600 \\
\hline ARBs, $n(\%)$ & $38(14.2)$ & $17(13.3)$ & $21(15.1)$ & 0.728 \\
\hline Beta blockers, n(\%) & $65(24.3)$ & $30(23.4)$ & $35(25.2)$ & 0.777 \\
\hline Loop diuretics, n(\%) & $41(15.4)$ & $18(14.1)$ & $23(16.5)$ & 0.613 \\
\hline ASS, $n(\%)$ & $52(19.5)$ & $23(18.0)$ & 29 (20.9) & 0.643 \\
\hline Antidepressants, n(\%) & $31(11.6)$ & $16(12.5)$ & $15(10.8)$ & 0.705 \\
\hline Statin, $n(\%)$ & $42(15.7)$ & $21(16.4)$ & $21(15.1)$ & 0.867 \\
\hline Corticosteroids & $66(24.7)$ & $35(27.3)$ & $31(22.3)$ & 0.395 \\
\hline
\end{tabular}

$A C E / A R B s$, angiotensin converting enzyme/angiotensin II receptor blockers; ASS, acetylsalicylic acid; $C A D$, coronary artery disease; $C R P$, C-reactive protein; ${ }^{8} F-F D G,{ }^{18} \mathrm{~F}$-fluorodeoxyglucose; $L V E F$, left ventricular ejection fraction; NT-proBNP, N-terminal pro-B-type natriuretic peptide; $S D$, standard deviation; SUV, standardized uptake value; $r S U V$, relative standardized uptake value. Data are presented as mean \pm SD or frequencies (percentage). Two-sided $P$-values are indicated 

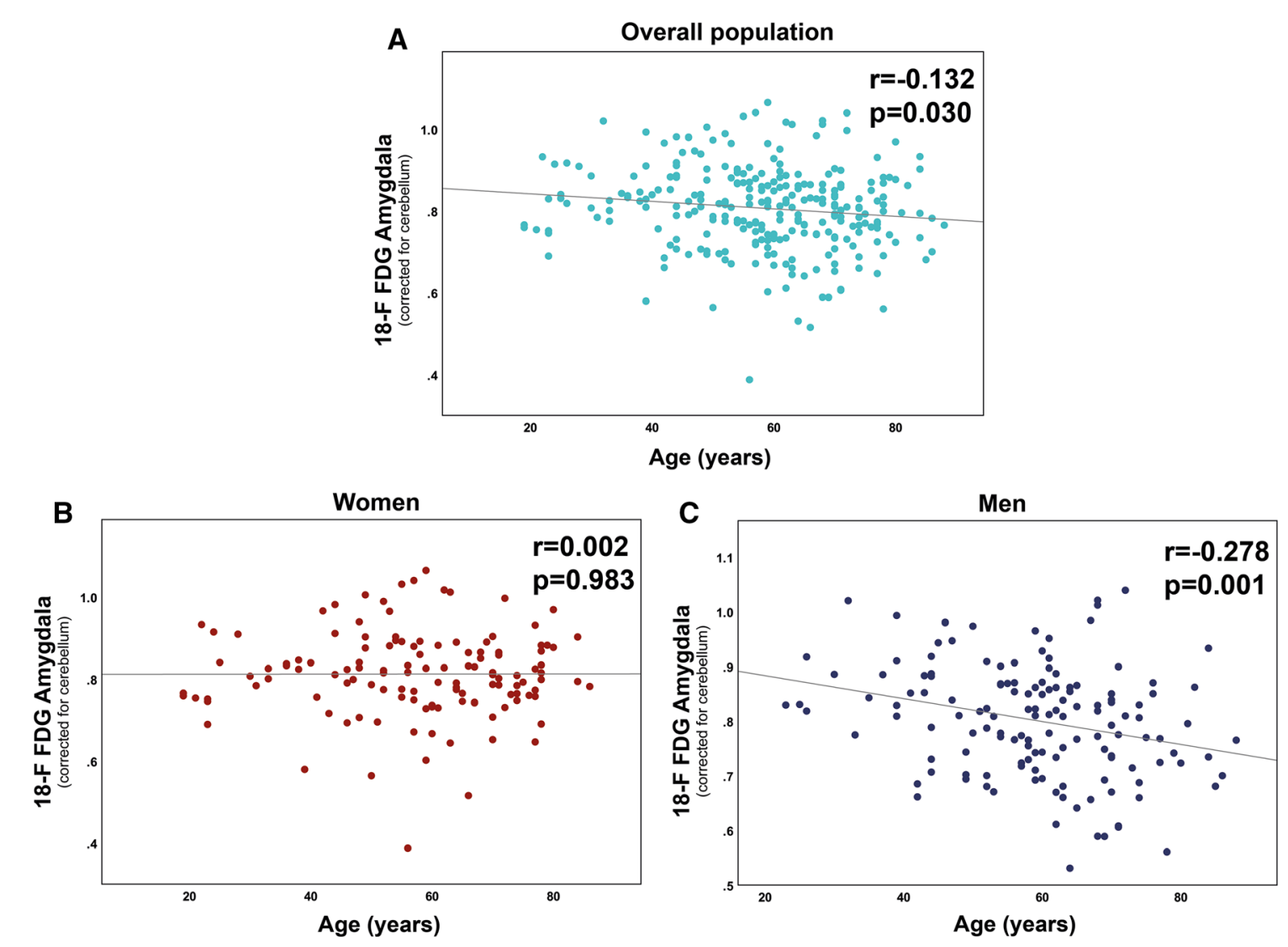

Figure 1. Correlation of amygdalar activity with age. A Pearson product-moment correlation reveals a gradual decline of amygdala metabolism during the aging process $(P=0.030)$ in the whole study population. C When stratified by sex, this correlation was significant in men $(P=0.001)$. B No correlation of amygdalar activity with age was observed in women $(P=0.983)$.

attenuated in elderly men, but not in elderly women, suggesting that women exhibit a persistently high neuronal stress level at older age. It is therefore tempting to hypothesize that chronic activation of the brain's salience network might predispose women to a higher cardiovascular vulnerability in situations of increased demand such as an acute coronary syndrome (ACS). Indeed, recent data indicate that women perceive greater emotional stress following an ACS and are more likely to develop mental-stress induced ischemia than men. ${ }^{10}$ Both observations emphasize the urgent need to account for psychosocial factors in primary and secondary prevention in women. ${ }^{2,11,12}$

As with any study, certain inherent design limitations should be pointed out. First, this study is a singlecenter retrospective analysis conducted in a cohort of aged individuals, which limits its generalizability. Second, our study is purely observational, and causality cannot be inferred from the associations shown. Third, although a comprehensive group of adjustment variables was employed, unmeasured factors affecting amygdalar metabolic activity, such as subclinical CAD and other nondetected cardiovascular conditions, as well as baseline differences between men and women, may have affected our endpoints. Fourth, given that patients were not specifically referred for assessment of cardio-neurological associations, a potential selection bias cannot be completely ruled out. Accordingly, the findings of this study are to be considered as hypothesis-generating and need to be confirmed in larger and, ideally, prospective studies.

In conclusion, our findings highlight that naturally occurring age- and sex-dependent changes need to be taken into consideration when using resting amygdalar activity as a risk stratification tool in patients with suspected or known CAD. Whether there is a direct link between adverse cardiovascular outcomes and chronic activation of the brain's salience network in aging women will have to be assessed in future studies. 

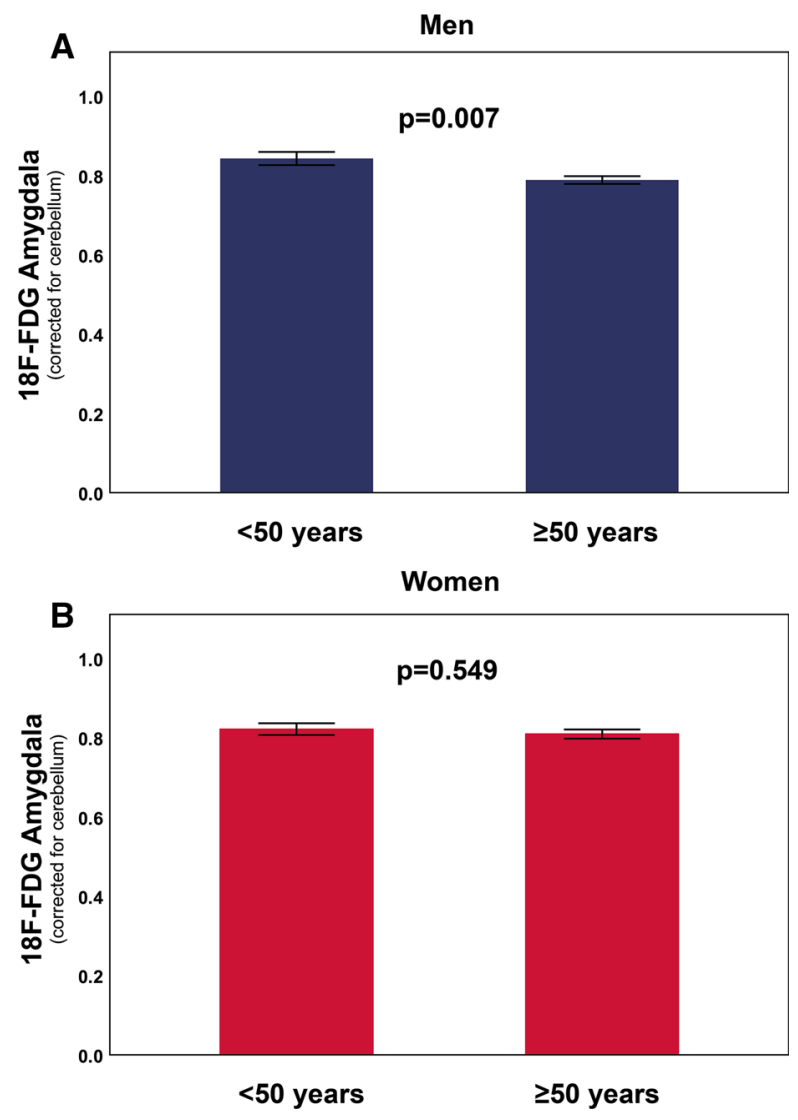

Figure 2. Age-dependent dichotomous assessment of resting amygdalar activity in men and women. A Amygdalar activity is significantly lower in men $\geq 50$ years of age $(P=0.007)$. B No age-dependent changes in amygdalar activity are observed in women $(P=0.549)$. Error bars indicate standard error, SE. $P$-values are depicted.

\section{NEW KNOWLEDGE GAINED}

Amygdalar metabolic activity declines with age in men, but not in women. Naturally occurring age- and sex-dependent changes in amygdalar metabolic activity need to be taken into consideration when using this metric as a risk stratification tool for patients with suspected or known CAD.

\section{Disclosure}

All authors have the following to disclose: The University Hospital of Zurich holds a research contract with GE Healthcare. $C G$ has received research grants from the Novartis Foundation and speaker's fees from Sanofi Genzyme, Switzerland.

\section{Ethical Approval}

The present study was approved by the local ethics committee (BASEC No. 2017-01112) and was conducted in agreement with the Declaration of Helsinki (including later amendments). The need for informed consent was waived due to the retrospective study design.

\section{Funding \\ Open Access funding provided by Universität Zürich.}

\section{Open Access}

This article is licensed under a Creative Commons Attribution 4.0 International License, which permits use, sharing, adaptation, distribution and reproduction in any medium or format, as long as you give appropriate credit to the original author(s) and the source, provide a link to the Creative Commons licence, and indicate if changes were made. The images or other third party material in this article are included in the article's Creative Commons licence, unless indicated otherwise in a credit line to the material. If material is not included in the article's Creative Commons licence and your intended use is not permitted by statutory regulation or exceeds the permitted use, you will need to obtain permission directly from the copyright holder. To view a copy of this licence, visit http://creativecommons.org/licenses/by/4.0/.

\section{References}

1. Townsend N, Wilson L, Bhatnagar P, Wickramasinghe K, Rayner M, Nichols M. Cardiovascular disease in Europe: Epidemiological update 2016. Eur Heart J 2016;37:3232-45.

2. Haider A, Bengs S, Luu J, et al. Sex and gender in cardiovascular medicine: presentation and outcomes of acute coronary syndrome. Eur Heart J 2019;41:1328-36.

3. Tawakol A, Ishai A, Takx RA, et al. Relation between resting amygdalar activity and cardiovascular events: A longitudinal and cohort study. Lancet 2017;389:834-45.

4. Fiechter M, Roggo A, Burger IA, et al. Association between resting amygdalar activity and abnormal cardiac function in women and men: A retrospective cohort study. Eur Heart J Cardiovasc Imaging 2019;20:625-32.

5. Templin C, Ghadri JR, Diekmann J, et al. clinical features and outcomes of takotsubo (stress) cardiomyopathy. New Engl J Med 2015;373:929-38.

6. Knuuti J, Wijns W, Saraste A, et al. 2019 ESC Guidelines for the diagnosis and management of chronic coronary syndromes: The Task Force for the diagnosis and management of chronic coronary syndromes of the European Society of Cardiology (ESC). Eur Heart J 2020;41:407-77.

7. Hammers A, Allom R, Koepp MJ, et al. Three-dimensional maximum probability atlas of the human brain, with particular reference to the temporal lobe. Hum Brain Mapp 2003;19:224-47.

8. Rosengren A, Hawken S, Ounpuu S, et al. Association of psychosocial risk factors with risk of acute myocardial infarction in 11119 cases and 13648 controls from 52 countries (the INTERHEART study): Case-control study. Lancet 2004;364:953-62.

9. Heidt T, Sager HB, Courties G, et al. Chronic variable stress activates hematopoietic stem cells. Nat Med 2014;20:754-8. 
10. Vaccarino V, Sullivan S, Hammadah M, et al. Mental stress-induced-myocardial ischemia in young patients with recent myocardial infarction: Sex differences and mechanisms. Circulation 2018;137:794-805.

11. Stewart AL, Kathawalla U-K, Wolfe AG, Everson-Rose SA. Women's heart health at mid-life: what is the role of psychosocial stress? Women's Midlife Health 2018;4:11.
12. Brezinka V, Kittel F. Psychosocial factors of coronary heart disease in women: A review. Soc Sci Med 1982;1996(42):1351-65.

Publisher's Note Springer Nature remains neutral with regard to jurisdictional claims in published maps and institutional affiliations. 